\title{
Os Direitos Humanos e o Regime Constitucional dos Tratados ${ }^{1}$
}

\section{Human rights and the constitutional regime of the treaties}

Alberto R. Dalla Via ${ }^{2}$

\begin{abstract}
RESUMO
A ampla reforma da Constituição argentina ocorrida em 1994 representa um ponto de inflexão importante na trajetória do regime constitucional dos tratados internacionais no país em questão. Estabelecendo tal reforma como marco fundamental, o presente trabalho tem como objetivo geral analisar seus principais desdobramentos no que respeita ao Direito Constitucional dos Tratados. Metodologicamente ancorado em análise de doutrina e jurisprudência, bem como em categorias como "bloco de constitucionalidade", "controle de convencionalidade" e "diálogo jurisprudencial", este trabalho revisita o embate entre as teses monista e dualista nas discussões sobre prevalência e hierarquia entre normas de direito interno e de direito internacional, com especial ênfase nas normas de tratados internacionais que versam sobre matéria de direitos humanos. Nesse sentido, o artigo focaliza as interfaces entre o sistema constitucional argentino e o Sistema Interamericano de Direitos Humanos (e, em particular, a Corte Interamericana de Direitos Humanos). Apesar de sua atenção recair sobre a experiência constitucional argentina, a produção doutrinária e jurisprudencial estrangeira, notadamente europeia, também compõe nossa análise. Por fim, são abordadas as principais repercussões das transformações sofridas pelo Direito Constitucional dos Tratados sobre o ensino jurídico argentino.
\end{abstract}

\section{PALAVRAS-CHAVE:}

Regime constitucional dos tratados; tratados internacionais; reforma constitucional; direitos humanos.

\begin{abstract}
The overarching reform of the Argentinian Constitution that took place in 1994 represents a major turn in the trajectory of the constitutional regime of international treaties in the concerned country. Taking such reform as a landmark, the primary goal of this work is to analyze the main implications regarding Constitutional Law of Treaties. Being methodologically anchored in the analysis of legal doctrine and case law, as well as in categories such as "block of constitutionality", "conventionality control", and "jurisprudential dialogue", this work revisits the conflict between the monist and dualist theses in the discussions about prevalence and hierarchy between rules of domestic law and international law, with a special emphasis on rules of international human rights treaties. In this regard, this paper focuses on the interfaces between the Argentinian constitutional regime and the Inter-American Human Rights Systems (and, particularly, the Inter-American Court of Human Rights). In spite of drawing attention to the
\end{abstract}

\footnotetext{
$\triangle$ Alberto R. Dalla Via

alberto.dalla-via@pjn.gov.ar

${ }^{1}$ Comunicação do autor realizada na Academia Nacional de Direito e Ciências Sociais de Buenos Aires, na sessão privada de 26 de setembro de 2019. Tradução da versão em espanhol, publicada na revista La ley em 1 de abril de 2020, para o português e com inclusão de referências bibliográficas realizadas por Daniela Cardoso, aluna da Faculdade de Direito da Universidade Federal Fluminense e estagiária do Tribunal Regional Federal da $2^{a}$ Região. Revisão por Ricardo Perlingeiro, Professor da Universidade Federal Fluminense e da Universidade Estácio de Sá e Desembargador Federal do Tribunal Regional Federal da $2^{a}$ Região.

${ }^{2}$ Presidente da Câmara Nacional Eleitoral. Doutor, pela Universidade de Buenos Aires, em Direito Constitucional (Faculdade de Direito) e em Ciência Política (Faculdade de Ciências Sociais). Professor Titular de Direito Constitucional (Faculdade de Direito, UBA). É Acadêmico de Número de Ciências Morais e Políticas e da Academia Nacional de Direito e Ciências Sociais de Buenos Aires.
} 
Argentinian constitutional experience, foreign legal doctrines and case law, notably from Europe, are also part of our analysis. Finally, we approach the main repercussions of the transformations undergone by the Constitutional Law of Treaties on the Argentinian legal education.

\section{KEYWORDS:}

Constitutional regime of treaties; international treaties; constitutional reform; human rights.

Após conhecer a decisão da Suprema Corte de Justiça da Nação no dossiê "Ministério de Relações Exteriores e Culto", em 14 de fevereiro de 2017, ${ }^{3}$ o jornal "El País", 4 da Espanha, publicou uma surpreendente nota de opinião do magistrado da Suprema Corte do México, Dr. José Ramón Cossío, classificando-a como um retrocesso para o Sistema Interamericano de Proteção dos Direitos Humanos, podendo o mesmo ser lido em comentários de alguns autores do nosso país, que interpretaram a decisão do nosso Supremo Tribunal como excessivamente formalista e apegada a categorias antigas.

Durante um seminário de Direito Internacional e Direito Comparado, no Instituto Max Planck de Heidelberg, do qual participei em março desse ano, ${ }^{5}$ muitos professores discutiram essa questão partindo de um pré-conceito. Com grande licença interpretativa, alguns especialistas entendem que, desde a reforma constitucional de 1994, e por via do art. 75, inc. 22, existiria uma receptividade direta do Direito Internacional no Direito Interno, sem qualquer reserva.

Nossa Constituição não adotou o modelo de prevalência do Direito Internacional sobre o Direito Interno, como fazem as Constituições da Holanda, do Paraguai (1992) e da Colômbia (1991). A história de um país de navegantes como a Holanda justifica essa posição, a partir da qual Hugo Grocio deu origem ao direito internacional. Não é o caso da Argentina, onde a reforma constitucional de 1994 adotou a tese "monista” já expressa nas decisões "Ekmekdjian

\footnotetext{
${ }^{3}$ ARGENTINA. Corte Suprema de Justicia de la Nacion. Ministerio de Relaciones Exteriores y Culto. Buenos Aires, 14 de fevereiro de 2017.

${ }^{4}$ DIAZ, José Ramón Cossío. Un mal día para el Sistema Interamericano. El País, Madri, fev. 2017.

${ }^{5}$ AGENDA EN EL SUR DE SURAMÉRICA: CRISIS, DIÁLOGO Y NUEVAS PERSPECTIVAS, 2 de março de 2017. Coloquio Iberoamericano. Instituto Max Planck, Heidelberg, 2017.
} 
c. Sofovich" e "Fibraca", ${ }^{7}$ deixando para trás as dúvidas que a redação do art. 31 e de uma anterior doutrina dualista ("Martín e Cia Ltda. AS c. Governo Nacional - Administração Gral. de Portos" ${ }^{\prime 8}$ ) geravam e que, inclusive, abrigou decisões controversas, como no caso "Merck Química Argentina c. Governo Nacional".9

Como apontou Vanossi, ${ }^{10}$ antes da reforma constitucional a discussão era se os tratados eram superiores às leis ou se o contrário. Depois da reforma, o regime constitucional dos tratados ampliou sua extensão e complexidade, registrando as seguintes categorias:

a) Tratados internacionais com hierarquia constitucional (os denominados no art. 75, inc. $22, \mathrm{CN}$ ou os agregados pelo sistema ali prescrito).

b) Outros tratados de direitos humanos, firmados e ratificados, mas que não integram a série do art. 75 , inc. $22, \mathrm{CN}$.

c) Tratados de integração com países da América Latina (art. 75, inc. 24, $1^{\mathrm{a}}$ parte, $\mathrm{CN}$ ).

d) Tratados de integração com países de outra região (art. 75, inc. 24, $2^{\mathrm{a}}$ parte, $\mathrm{CN}$ ).

e) Tratados internacionais (superiores às leis, art. 75, inc. 22, CN).

f) Tratados internacionais que os Estados podem firmar (art. 124, CN).

g) Outros tratados: tratados bilaterais de inversão, acordos executivos, etc.

Em nossa doutrina há distintas posições e algumas geram confusão, como o "bloco de constitucionalidade" que os alunos frequentemente repetem nas mesas de exames e que não raro aparecem como "slogan", obrigatório, mas geralmente impreciso. Essa expressão corresponde ao que dizem o professor francês Louis Favoreau ${ }^{11}$ e o espanhol Francisco Rubio Llorente, ${ }^{12}$ adotando uma tendência existente no Direito Comparado Europeu, em que se incorporam distintas leis e normas comunitárias que prevalecem sobre o direito dos Estados locais e das comunidades autônomas. Uma expressão similar também já havia sido utilizada

\footnotetext{
${ }^{6}$ ARGENTINA. Corte Suprema de Justicia de la Nacion. Ekmekdjian c. Sofovich. Buenos Aires, 7 de julho de 1992.

${ }^{7}$ ARGENTINA. Corte Suprema de Justicia de la Nacion. Fibraca Constructora SCA c/Comisión Técnica Mixta de Salto Grande. Buenos Aires, 7 de julho de 1993.

${ }^{8}$ ARGENTINA. Corte Suprema de Justicia de la Nacion. Martín \& Cia. Ltda. SA c. Nación. Buenos Aires, 6 de setembro de 1953.

${ }^{9}$ ARGENTINA. Corte Suprema de Justicia de la Nacion. Merck Química Argentina c. Governo Nacional. Buenos Aires, 9 de junho de 1948.

${ }^{10}$ VANOSSI, Jorge Reinaldo A.; DALLA VIA, Alberto Ricardo. Régimen constitucional de los tratados. Buenos Aires: Abeledo Perrot, 2000.

${ }^{11}$ FAVOREAU, Louis. El bloque de la constitucionalidad. Revista del Centro de Estudios Constitucionales, n.5, p. 45, ene./mar. 1990.

${ }^{12}$ LLORENTE, Francisco Rubio. El bloque de la constitucionalidad. Revista Española de Derecho Constitucional, n. 27 , p. 9, set./dez. 1989.
} 
em nossa doutrina para explicar que a primeira parte do art. 31 continha um "bloco" de direito federal que prevalece sobre o Direito Público Provincial.

Como o direito é uma ciência social e não uma ciência exata, existe certa margem de amplitude na utilização de conceitos e classificações que podem ser úteis na medida em que respondam ao contexto em que devam se aplicar, de modo que a ideia do "bloco de constitucionalidade" poderia ser um rótulo útil sem que necessariamente se identifique com o conceito de Favoreau e Rubio Llorente.

Germán José Bidart Campos foi um professor dos mais influentes. Em seus primeiros anos se dedicou ao Direito Constitucional e nos últimos ocupou a cátedra de Direitos Humanos e Garantias, antes de culminar como professor emérito da Universidade de Buenos Aires. Seguindo Werner Goldschmidt, defendeu a tese monista, segundo a qual os tratados internacionais deviam prevalecer sobre as leis ditadas pelo Congresso. Sua posição foi predominante na reforma constitucional de 1994.

$\mathrm{O}$ art. 75 , inc. $22,{ }^{13}$ ao se referir à aprovação dos tratados internacionais pelo Congresso, disse expressamente que os tratados são superiores às leis. Nesse ponto, não há dúvidas, mas onde se tem suscitado disputas interpretativas é no que concerne aos tratados de direitos humanos com hierarquia constitucional. A jurisprudência da Suprema Corte utiliza a expressão "bloco de constitucionalidade", gerando confusão toda vez que alguns autores sustentam que, a partir da reforma, a operatividade dos tratados internacionais de direitos humanos é direta num espectro igual - ou até superior - à Constituição.

Chegou-se a sustentar que o referido "bloco de constitucionalidade" é uma norma aberta e que, conforme o princípio pro homine e o princípio da boa-fé dos tratados internacionais, podiam considerar-se compreendidos no "bloco" até os tratados de direitos humanos não firmados nem ratificados em nosso país. Para sustentar um argumento tão amplo, citava-se o art. 33 da CN, referindo-se aos "direitos não enumerados" que alguns traduzem como "direitos implícitos".

\footnotetext{
${ }^{13}$ Art. 75, inc. 22 da Constitución de la Nación Argentina.
} 
Uma parte da doutrina segue seus próprios rumos, chegando a extremos como a jurisprudência dos casos "Mazzeo"14 e "Simón"15, que admitiram o valor do costume internacional sobre o texto do art. 18 da CN, com a dissidência dos Drs. Carlos Fayt e Carmen Argibay e a crítica da Academia Nacional de Direito, com motivos fundados e relevantes, que também vemos expostos em diversos trabalhos sobre a matéria.

No sistema constitucional argentino, a ordem pública suprema é a Constituição Nacional, que ocupa o ponto mais alto da pirâmide jurídica. Os tratados de direitos humanos têm "hierarquia constitucional", "nas condições de sua vigência" e não revogam nenhum item da primeira parte, mas são "complementares". São aqueles que se encontram enumerados no texto constitucional, somados aos que o Congresso Nacional incorpore, conforme o procedimento especial ali estabelecido.

A "hierarquia constitucional" reside no fato de os referidos tratados não poderem ser declarados inconstitucionais pelos juízes, porque o exame de constitucionalidade já foi realizado pelo constituinte no momento de incorporá-los, ou pelo Congresso em cada incorporação particular, conforme a doutrina da Suprema Corte de Justiça expressa no caso "Giroldi". 16

É um dado da realidade que a expressão "bloco de constitucionalidade" se encontra muito difundida, mas não é menos aceitável que uma interpretação saudável exija localizá-la em seu lugar, não para diminuir seu valor e importância, mas para evitar interpretações muito abertas que fogem ao contexto e colocam em crise todo o sistema jurídico. Quando o art. 33 admite direitos não enumerados, mas que surgem do "princípio da soberania do povo" e da “forma republicana de governo", está marcando dois eixos ou parâmetros para direitos de participação no modelo de democracia representativa, mas não está ampliando a fonte normativa nem estendendo um critério ilimitado para o reconhecimento destes direitos.

Deve-se recordar que a Convenção de Viena Sobre Direito dos Tratados de 1969 é um tipo de "Código Processual" dos tratados internacionais e expressa que tais instrumentos devem

\footnotetext{
14 ARGENTINA. Corte Suprema de Justicia de la Nacion. Mazzeo, Julio Lilo y otros s/ rec. de casación e inconstitucionalidad-Riveros. Buenos Aires, 13 de julho de 2007.

${ }^{15}$ ARGENTINA. Corte Suprema de Justicia de la Nacion. Simon, Julio Héctor y otros s/ privación ilegítima de la libertad, etc. (Poblete) - causa $n^{\circ}$ 17.768. Buenos Aires, 14 de junho de 2005.

${ }^{16}$ ARGENTINA. Corte Suprema de Justicia de la Nación. Giroldi, Horacio David y otro s/ recurso de casacióncausa n. 32/93. Buenos Aires, 7 de abril de 1995.
} 
se entender conforme o sentido estrito de sua literalidade e não em sentido amplo, por serem produto de acordos complexos.

O controle de convencionalidade surge da jurisprudência da Corte Interamericana de Direitos Humanos a partir do caso "Almonacid Arellano e outros vs. Chile"17 e foi reconhecido por nossa Suprema Corte; no entanto, juízes nacionais podem fazer valer a dita Convenção quando derem solução a questões jurídicas a resolver dentro do direito interno do país. É uma doutrina que se aprofunda no caráter operativo da Convenção.

Trata-se de uma obviedade, com muito "marketing" no mundo jurídico, mas de uma grande obviedade, no fim das contas. O controle de convencionalidade não é outra coisa, para nosso Direito Interno, senão a aplicação do controle de constitucionalidade para o caso em que os tratados de direitos humanos com hierarquia constitucional - no caso da Convenção Americana de Direitos Humanos - entrem em colisão com normas inferiores de nosso ordenamento jurídico (leis, decretos, etc.), fazendo prevalecer a ordem de hierarquia normativa que surge do art. 31 da $\mathrm{CN}$.

O "controle de convencionalidade" parte da crença de que não somente os juízes da Corte de São José da Costa Rica velam pela aplicação dessa Convenção, mas que todos os juízes nacionais dos Estados membros o fazem, tanto que a Convenção se encontra incorporada ao ordenamento jurídico interno em um grau superior.

Seu alcance deve ser o regime constitucional dos tratados que surge do art. 27 de nossa $\mathrm{CN}$, favorecendo-se pela incorporação, ao direito interno, de instrumentos internacionais que afirmam os princípios de autonomia pessoal, de não interferência e de dignidade da pessoa humana que nosso ordenamento constitucional proclama para todos os homens - e mulheres do mundo que queiram habitar o solo argentino.

Coincidimos com a opinião do professor Armin Von Brogdandy, ${ }^{18}$ do Instituto Max Planck de Heidelberg, quando afirma que o importante é dar o maior nível de proteção efetiva aos direitos fundamentais, seja através da intervenção dos tribunais internacionais ou dos juízes

\footnotetext{
${ }^{17}$ CORTE INTERAMERICANA DE DERECHOS HUMANOS (Corte IDH). Caso Almonacid Arellano y outros vs. Chile. San José, Costa Rica, 26 de setembro de 2006.

${ }^{18}$ BROGDANDY, Armin Von. Ius constitutionale commune In: MAC-GREGOR, Eduardo Ferrer; RAMÍREZ, Fabiola Martínez; MEJÍA, Giovanni A. Figueroa (Coord.). Diccionario de Derecho Procesal Constitucional y Convencional. 2 ed. México: Instituto de investigaciones jurídicas, 2014. p. 774-777.
} 
nacionais; muitas vezes são estes últimos que garantem um maior nível de proteção, devido aos distintos níveis de evolução de cada ordenamento jurídico.

De outro lado, há outros autores que partem do princípio de um maior nível de proteção garantido pelos tribunais internacionais frente ao direito interno dos Estados, sobre os quais existe um princípio de desconfiança. Sagüés, ${ }^{19}$ inclusive, sustenta que a ordem internacional é melhor que a ordem interna.

Para Carlos Ayala Corao, ${ }^{20}$ o "controle de convencionalidade" é o resultado de um “diálogo jurisprudencial” entre os tribunais internacionais e as cortes nacionais que vai se mantendo em direção à adoção de parâmetros comumente aceitos, um tipo de cross-fertilization entre tribunais. Um exemplo é o "controle de proporcionalidade", alheio a nossas tradições jurídicas, mas que aterrissa em nossa literatura vindo de uma criação prussiana, trasladada ao Tribunal Europeu de Direitos Humanos de Estrasburgo e, dali, à Corte de São José da Costa Rica. Para o atual presidente da Corte Interamericana de Direitos Humanos, o mexicano Eduardo Ferrer Mc Gregor, ${ }^{21}$ existiria um "Direito Processual Constitucional da Liberdade de caráter supranacional".

Essas doutrinas sustentam uma certa superioridade moral do Direito Internacional sobre o Direito Interno e, a nosso juízo, não alcançam uma resposta adequada e precisa para solucionar nossos problemas, embora resultem aplicáveis a outros ordenamentos jurídicos da América Latina. Há um ponto de partida de "desconfiança" para ordenamentos e em direção às instituições do direito interno.

Pelo contrário, uma má ou inadequada percepção do controle de convencionalidade como instrumento pode levar a confusões, começando por interpretar uma primazia hierárquica do Direito Internacional sobre o Direito Interno; clássica discussão atual entre internacionalistas e constitucionalistas, que resulta em uma espécie de disputa de poder, mas que pode servir mais

\footnotetext{
19 SAGUES, Néstor Pedro. La interpretación de los derechos humanos en las jurisdicciones nacional e internacional. Anticipo de "anales", segunda época, año XLII, n.36, Buenos Aires, p. 14-15, 1998.

${ }^{20}$ CORAO, Carlos Ayala. Del diálogo jurisprudencial al control de convencionalidad. Caracas: Editorial Jurídica Venezolana, 2012. (Colección de Estudios Jurídicos, n.98).

${ }^{21}$ Mc GREGOR, Eduardo Ferrer. Panorámica del Derecho Procesal Constitucional y Convencional. Madri, Barcelona, Buenos Aires, São Pablo: Instituto de Investigaciones Jurídicas - UNAM, Marcial Pons, 2013.
} 
para confundir do que para conceder ao ordenamento jurídico os níveis necessários de certeza e de segurança jurídica.

Um exemplo é a reforma do Código Civil e Comercial da Nação que enunciou como um de seus paradigmas a "constitucionalização do direito privado", buscando uma adequação do direito de fundo com a reforma constitucional de 1994 e sua compatibilidade com os tratados de direitos humanos com hierarquia constitucional. Devido à interpretação das várias questões inovadoras tratadas pela reforma, estará a cargo dos juízes das instâncias ordinárias explicar devidamente o alcance do "controle de convencionalidade" para que não seja outra vez patrimônio de interpretações extensivas, que às vezes impõe um certo "esnobismo" ao se nutrir de inovações sem reparar adequadamente seus alcances.

A "margem de apreciação nacional” é uma doutrina utilizada pelo Tribunal Europeu de Direitos Humanos de maneira subsidiária e sem correlato na Corte Interamericana de Direitos Humanos. Com efeito, as sentenças do TEDH têm uma natureza declarativa. Como disse Pablo Antonio Fernández Sánchez ${ }^{22}$ : “são sempre juridicamente obrigatórias, mas nunca executórias", dadas as mesmas limitações de uma comunidade internacional, que carece de órgãos executivos centralizados, e, dado que se deve deixar uma liberdade de eleição de meios aos Estados para assegurar o cumprimento das sentenças, sua execução torna-se uma obrigação de resultado, um compromisso internacional para os Estados, que devem tomar as medidas necessárias para que as violações não se repitam, o que inclui, se necessário, modificações da legislação que transcendam o caso concreto julgado.

O seguimento da execução das sentenças do TEDH é realizado pelo Comitê de Ministros do Conselho Europeu, enquanto a execução das sentenças da Corte IDH é seguida e controlada pela mesma. Em outras palavras, no primeiro caso nos encontramos diante de um sistema de seguimento do cumprimento de sentenças de natureza política, próprio de um tratado internacional de pós-guerra, como é o Convênio Europeu de Direitos Humanos, que começa dizendo que está celebrado entre “Altas Partes Contratantes". Por outro lado, por ser a Corte IDH um produto da terceira onda de democratização, é ela quem marca o seguimento da execução de suas próprias sentenças, sendo o procedimento mais judicial e de maior rigor na

\footnotetext{
${ }^{22}$ SÁNCHEZ, Pablo Antonio Fernández. Naturaleza jurídica de las sentencias del TEDH y del TJCE. In: ROCA, Javier García; SÁNCHEZ, Pablo Antonio Fernández (Coord.). Integración europea a través de derechos fundamentales: de un sistema binario a otro integrado. [S.1.]: Ed. La Jurídica, 2009.
} 
exigência de seu cumprimento, de modo que a Corte IDH segue um critério mais exigente na aplicação de suas decisões em cada um dos países.

A elaboração de uma doutrina sobre o "controle de convencionalidade", a que fizemos referência ut supra, é também uma consequência dessa atitude do tribunal regional, doutrina que não tem comparação na Europa. A contrario sensu a doutrina da margem de apreciação nacional tem raízes na Europa, mas não na América Latina, uma vez que o tribunal americano pretende influenciar o direito interno dos países e não se esquivar de fazê-lo.

O professor da Universidade Complutense Javier García Roca tem estudado o tema com profundidade, afirmando que a margem implica "uma certa diferença para garantia nacional". ${ }^{23}$ Por exemplo, um barco que navega sobre as águas do Convênio Europeu, mas sem perder de vista a costa, que é o Direito de cada país. Por isso, a "diferença" é um conceito diplomático que considera a importância e o nível de desenvolvimento jurídico de cada nação. Para dizer com suas palavras,

[...] a margem de apreciação nacional implica uma certa discricionariedade dos Estados como uma regra de não decisão, um tipo de diferença europeia para a decisão interna; O tribunal de Estrasburgo pode em certos casos não julgar plenamente o assunto e ratificar a decisão nacional. ${ }^{24}$

De modo complementar, Johan Callewaert tem explicado que a "margem de apreciação nacional" expressa "uma forma atenuada de imunidade que permite o controle europeu menos intenso que aquele que a Corte poderia exercer no desempenho da plenitude de sua jurisdição" 25; e Wildhaber tem diversificado essa explicação, dizendo que não se trata de conceder um nível de discricionariedade aos Estados frente a situações que em outros casos suporiam violações do Convênio, mas "simplesmente de reconhecer que o Convênio não impõe soluções uniformes" e que "em certos domínios, e só em certo nível, os Estados podem ter diferentes regulações e restrições". ${ }^{26}$

\footnotetext{
${ }^{23}$ ROCA, Javier García. El margen de apreciación nacional en la interpretación del Convenio Europeo de Derechos Humanos: Soberanía e integración. Cizur Menor, Navarra: Cuadernos Cívitas, Instituto de Derecho Parlamentario, Thomson Reuters, 2010.

${ }^{24}$ Ibid.

${ }^{25}$ CALLEWAERT, Johan. Quel avenir pour la marge d'appréciation?. In: MAHONEY, Paul; MATSCHER, Franz; PETZOLD, Herbert; WILDHABER, Luzius (Eds.). Protecting Human Rights. Colonia, Berlin, Munich: Carl HeymannsVerlag, 2000. p. 149.

${ }^{26}$ ROCA, op. cit., p. 114-115.
} 
A “margem de apreciação nacional" é uma doutrina de raiz europeia, utilizada com muita frequência pelo TEDH e rejeitada pela Corte IDH. Como demonstramos em um trabalho de investigação, o TEDH tem pronunciado muitas sentenças em matéria de direitos políticos e eleitorais, quanto às regras do devido processo eleitoral em países da Europa Oriental, tardiamente inseridos no âmbito do Conselho da Europa, mas se observam poucas sentenças contra países mais poderosos como Inglaterra, França e Alemanha.

Embora García Roca tenha se esforçado para descartar como "falsa tese" a soberania irrestrita como imunidade jurisdicional, pensamos que a soberania continua desempenhando seu papel, especialmente quando se traduz como supremacia da Constituição no Direito Interno. Assim, aparece refletido em pronunciamentos distintos do Sistema Interamericano de Direitos Humanos (SIDH), no âmbito da Comissão e da Corte Interamericana, assim como no sistema eleitoral de cada país. Um exemplo têm sido as propostas de "candidaturas independentes", assim a Comissão no Caso "Antonio Ríos"27; e a Corte, em "Castañeda Gutman vs. Estados Unidos Mexicanos", ${ }^{28}$ consideraram que cada país devia projetar seu próprio sistema de candidaturas quando se tratava de Argentina e México, mas, em "Yatama v. Nicaragua", 29 considerou que o monopólio da representação por partidos devia ceder em face do multiculturalismo das comunidades indígenas.

A “margem de apreciação nacional" não é uma doutrina aplicada em nosso domínio. Uma coisa é a primazia do art. 27 como reafirmação do art. 31 na ordem pública da Constituição quando se aplica a tratados internacionais, mas a "margem de apreciação nacional" é outra coisa; é uma doutrina do TEDH de diferença para o direito dos Estados membros, mas não o inverso, uma doutrina invocada desde os tribunais nacionais. No Direito sempre é bom chamar as coisas por seu nome.

Uma maneira de poupar dramatismo à decisão da Suprema Corte é "Fontevecchia", ${ }^{30}$ é determinar exatamente o ponto de sua decisão, sem excesso. É necessário recordar que a

\footnotetext{
${ }^{27}$ COMISIÓN INTERAMERICANA DE DERECHOS HUMANOS (CIDH). Resolución $n^{\circ}$ 26/88, caso 10109 . Argentina, setembro de 1988.

${ }^{28}$ CORTE INTERAMERICANA DE DERECHOS HUMANOS (Corte IDH). Caso Castañeda Gutman vs Mexico, Serie C $n$ 184. São José, Costa Rica, 6 de agosto de 2008.

${ }^{29}$ CORTE INTERAMERICANA DE DERECHOS HUMANOS (Corte IDH). Caso Yatama v. Nicaragua. San José, Costa Rica, 23 de junho de 2005.

${ }^{30}$ CORTE INTERAMERICANA DE DERECHOS HUMANOS (Corte IDH). Caso Fontevecchia. São José, Costa Rica, 29 de novembro de 2011.
} 
Suprema Corte ratificou o cumprimento das obrigações internacionais da Argentina no enquadramento do art. 68 da Convenção, uma vez que no segundo ponto condena o Estado Nacional a restituir a Fontevecchia e D'Amico os valores pagos tempestivamente ao expresidente Carlos Menem, mais as atualizações e os gastos processuais.

Por outro lado, a Suprema Corte se afastou da decisão da Corte IDH somente no enquadramento do art. 63, que se refere aos aspectos alternativos do cumprimento de sentença; entendendo a Suprema Corte de Justiça da Nação que a Corte IDH foi mais além do texto do art. 63, que deve ser interpretado em sua literalidade, conforme expressa a Convenção de Viena sobre Direito dos Tratados, mas que tem sido matéria de uma prática expansiva da Corte da Costa Rica, na fase de controle de cumprimento das sentenças, infringindo, a critério da Corte, o domínio de competência como órgão de aplicação do Tratado, introduzindo questões de interpretação sobre o Direito Constitucional argentino, que corresponde à Suprema Corte como última autoridade na matéria.

Em particular, nosso Supremo Tribunal recorda à Corte IDH que não é um tribunal de cassação, nem um tribunal de revisão das sentenças da Suprema Corte de Justiça passadas em autoridade de coisa julgada e que, portanto, se encontram firmes.

A Corte insistiu em uma questão formal: suas sentenças não se "revogam" por uma instância internacional, em todo caso trata-se de domínios distintos no cumprimento do tratado, mas, na ordem jurídica interna, a Corte é "suprema" e não admite nenhuma autoridade judicial superior a ela.

Cabe lembrar que a Constituição Nacional utiliza duas vezes a expressão "suprema". A primeira é para se referir ao presidente como "Chefe Supremo da Nação", no art. 99, inc. 1", expressão que remonta aos tempos de Justo José de Urquiza; e, ao iniciar a seção correspondente ao Poder Judiciário, no art. 108, quando diz que o mesmo se constitui com a "Suprema Corte de Justiça" e os demais tribunais inferiores que estabelecem o Congresso no território da Nação.

Embora a questão pareça ser formal e em algum aspecto terminológica, tem importância quanto ao posicionamento da Corte em sua última integração, aparecendo claras as posições dos ministros Rosenkrantz e Rosatti - este último com ênfase acentuada - e marcando uma 
alteração no então presidente Lorenzetti e a vice-presidente Highton de Nolasco com respeito a pronunciamentos anteriores. Apenas o ministro Maqueda persistiu na jurisprudência anterior.

Um ponto que não deve deixar de se considerar na análise é que a jurisprudência da Corte, em sua composição anterior, alcançou níveis expressivos, sobretudo nas questões vinculadas aos crimes contra a humanidade, que foram uma bandeira política dessa etapa que a Corte acompanhou e sobre a qual se manifestou formalmente em precedentes como "Mazzeo" "31 e "Simón" 32 , nos quais o Supremo Tribunal sustenta que o costume internacional prevalecia sobre o texto do art. 18 da Constituição, que sustenta desde os tempos do decreto de Seguridade Individual de $1811^{33}$, escrito por Mariano Moreno e aprovado pelo Primeiro Triunvirato, que ninguém pode ser julgado duas vezes pelo mesmo fato (non bis in idem); tal decisão contou com as dissidências da Dra. Carmen Argibay e do Dr. Carlos Santiago Fayt e foi duramente criticada pela Academia Nacional de Direito.

Não é plausível sustentar que a Corte queira retroceder em matéria de Direitos Humanos, eles são um valor precioso no Direito Constitucional argentino, mas acreditamos que a Corte deve acrescentar um atributo inteligente e necessário em uma questão formal de interpretação que não é menor nem irrelevante. O Supremo Tribunal nos recorda o que muitos pareciam ter esquecido, que é o art. 27, CN, a norma fundamental nesta matéria.

A razoabilidade começou a surgir quando, no parágrafo 21 da resolução de 18 de outubro de 2017, ${ }^{34}$ a Corte Interamericana interpretou que o Estado Argentino podia cumprir com sua ordem original mediante "algum outro tipo de ato jurídico, diferente da revisão de sentença" como, por exemplo, a realização de uma "anotação indicando que essa sentença foi declarada violadora da Convenção Americana pela Corte Interamericana”.

A Suprema Corte entendeu que a interpretação formulada pela Corte Interamericana é consistente com sua decisão de fevereiro de 2017, já que uma medida como a sugerida não viola

\footnotetext{
${ }^{31}$ ARGENTINA. Corte Suprema de Justicia de la Nacion. Mazzeo, Julio Lilo y otros s/ rec. de casación e inconstitucionalidad - Riveros. Buenos Aires, 13 de julho de 2007.

${ }^{32}$ ARGENTINA. Corte Suprema de Justicia de la Nacion. Simon, Julio Héctor y otros s/ privación ilegítima de la libertad, etc. (Poblete) - causa $n^{\circ} 17.768$. Buenos Aires, 14 de junho de 2005.

${ }^{33}$ ARGENTINA. Triunvirato. Decreto de Seguridad Individual, de 23 de novembro de 1811. En Estatutos, 1961, p. 29.

${ }^{34}$ CORTE INTERAMERICANA DE DERECHOS HUMANOS (Corte IDH). Caso Fontevecchia y D'amico vs. Argentina. Supervisión de cumplimiento de sentencia. Resolución de la Corte Interamericana de Derechos Humanos de 18 de outubro de 2017.
} 
os princípios de Direito Público estabelecidos no art. 27 da CN. Por esse motivo, ordenou que fosse colocada a seguinte legenda junto à decisão registrada no julgamento 324:2895: "Esta sentença foi declarada incompatível com a Convenção Americana de Direitos Humanos pela Corte Interamericana (sentença de 21 de novembro de 2011)". ${ }^{35}$ A decisão foi subscrita pelos ministros Lorenzetti, Higton de Nolasco, Rosatti e Rosenkrantz.

Nesta matéria, assim como no referido julgamento, subjaz uma questão fática, a saber, a prevalência do Direito Constitucional ou do Direito Internacional. Trata-se, por fim, de determinar quem tem a última palavra quando se está diante de um conflito pela aplicação de um tratado constitucional no direito interno. Assim tem assinalado Calógero Pizzolo em seu livro "Comunidade de intérpretes finais: Relação entre tribunais supranacionais, constitucionais e supremos. O diálogo jurídico". ${ }^{36}$

A Convenção de Viena sobre Direito dos Tratados de 1969 estabelece que nenhum Estado pode alegar fundamentos de seu Direito Interno para desconhecer obrigações assumidas na ordem internacional; de tal modo que esse princípio expresso no art. 27 da referida Convenção manteria uma contradição aparente com o art. 27 de nossa $\mathrm{CN}$ quando assinala que os tratados internacionais devem respeitar a ordem pública da Constituição. Trata-se de uma contradição aparente, e não só numérica, que se resolve a partir da ordem hierárquica das fontes e, em nosso ordenamento, prevalece o princípio da supremacia constitucional.

Alega-se uma "crise da soberania" que se manifesta nos processos de universalização do direito, como nos processos de integração jurídica e de globalização como fenômeno, de maneira que, na ordem internacional, o conceito de soberania e independência tem acomodado a ideia de "interdependência". Esta realidade é a que se manifesta dentro de uma faixa estreita em que se alojam estes conflitos interpretativos.

Immanuel Kant, em seu discurso "Sobre a Paz Perpétua", ${ }^{37}$ bem como Juan Bautista Alberdi, em "O Crime da Guerra", ${ }^{38}$ advogaram por um governo universal que pusesse fim aos conflitos. São utopias que não alcançaram realização prática, apesar dos distintos e valiosos

\footnotetext{
${ }^{35}$ ARGENTINA. Corte Suprema de Justicia de la Nacion. Resolución $n^{\circ}$ 4015/17. Buenos Aires, 5 de dezembro de 2017.

36 PIZZOLO, Calogero. Comunidad de intérpretes finales Relación entre tribunales supranacionales, constitucionales y supremos. El Diálogo Judicial. Buenos Aires: Astrea, 2017.

${ }^{37}$ KANT, Immanuel. Sobre la paz perpetua. Madri: Alianza, 2002.

${ }^{38}$ ALBERDI, Juan Bautista. El crimen de la guerra. [S.1.]: Ed. Librería Histórica, 2004.
} 
esforços de cooperação internacional, especialmente a partir da Segunda Guerra Mundial. Mas foi Hans Kelsen, em sua "Teoria Geral sobre o Direito e o Estado, ${ }^{39}$ quem se encarregou com solidez de destacar que o monopólio da coação e da criação de normas jurídicas obrigatórias continua nas mãos do Estado.

O Direito Internacional Público segue carecendo de força interpretativa e o ius cogens segue sendo sua fonte normativa essencial, com forte apego ao costume, à boa-fé e à reciprocidade de tratamento entre as Nações. Esse é o motivo pelo qual Jean Bodin, que foi um teórico clássico do Estado-Nação, de origem monárquica, considerava a obrigatoriedade de cumprir com seus tratados internacionais, precisamente por ser a palavra empenhada do monarca ou do soberano; de onde resulta que o cumprimento dos compromissos internacionais não é contraditório nem incompatível com a ideia de soberania nem com a supremacia da Constituição, mas, pelo contrário, é a mesma base de sua obrigatoriedade, derivada do compromisso assumido no direito interno. ${ }^{40}$

Ao recuperar a democracia em 1983, nosso país voltou a colocar em vigência a Constituição Nacional que não havia vigorado durante os anos obscuros. A parte "dogmática" é de grande amplitude e a doutrina coincidia amplamente no entendimento de que os princípios de liberdade, igualdade, autonomia e dignidade da pessoa eram suficientemente explícitos para a proteção dos direitos fundamentais; a Suprema Corte, inclusive, desenvolveria uma jurisprudência avançada baseando-se principalmente no art. 19.

A aprovação e a ratificação da Convenção Americana de Direitos Humanos ou "Pacto de São José da Costa Rica" e dos Pactos de Direitos Civis, Políticos, Econômicos, Sociais e Culturais da ONU pela República Argentina foram uma importantíssima incorporação jurídica, mas foram também um forte gesto político democrático por parte do governo do presidente Alfonsín, que se complementou com outras medidas como a criação das cátedras de "Direitos Humanos" na Faculdade de Direito da Universidade de Buenos Aires e em outras universidades nacionais.

De acordo com o plano de estudos, o ensino do Direito Constitucional se dividiu em duas partes, substituindo o anterior programa de Direito Constitucional I (Teoria Constitucional

\footnotetext{
${ }^{39}$ KELSEN, Hans. Teoría General del Derecho y del Estado. México: UNAM, 1979.

${ }^{40}$ BODIN, Jean. Los seis libros de la Republica. 4 ed. Madri: Ed. Tercer Milenio Tecnos, 2006.
} 
e Direito Constitucional Comparado) e Direito Constitucional II (Direito Constitucional Argentino).

A partir da reforma, a primeira parte passou a se chamar "Elementos de Direito Constitucional" e a segunda parte "Direitos Humanos e Garantias", compreendendo esta última tanto a parte dogmática da Constituição Nacional como os instrumentos internacionais de proteção; com a particularidade de que os conteúdos da disciplina se encontravam divididos nesses três terços que correspondiam ao Direito Constitucional, à Filosofia do Direito e ao Direito Internacional respectivamente, sendo os três primeiros professores titulares da cátedra recém-criada, um de cada especialidade, os doutores Germán J. Bidart Campos, Eduardo Rabossi e Raúl Vinuesa, respectivamente.

Com o transcurso do tempo se observa que ao longo destes anos foram os professores de Direito Internacional que cobraram maior ingerência no ditado dessa matéria que foi se voltando essencialmente para os instrumentos regionais e internacionais de proteção, em detrimento da carga horária destinada ao ensino do Direito Constitucional propriamente dito, ao menos durante a etapa inicial da carreira.

O ensino do próprio Direito Internacional tem sofrido profundas transformações, uma vez que existia anteriormente uma divisão entre o "Direito Internacional Público" e o "Direito Internacional Privado", sendo que este último tem se subsumido no primeiro, que já não se ocupa somente das relações entre os Estados, mas também das relações particulares a partir da difusão do princípio pro homine. Estas razões não são apenas acadêmicas, mas ajudam na difusão do "bloco de constitucionalidade" e do "controle de convencionalidade" na aplicação prática da doutrina.

As discussões acadêmicas entre constitucionalistas e internacionalistas muitas vezes se trasladam à doutrina e à jurisprudência dos tribunais, como no caso que comentamos, em que subjaz uma questão de fundo: Quem manda? A Suprema Corte tem dado uma resposta em sua sentença quando afirma que ela é a autoridade máxima em matéria de interpretação da Constituição Nacional e que a Corte Interamericana é a autoridade máxima em matéria de interpretação da Convenção Americana de Direitos Humanos. 


\section{REFERENCIAS}

AGENDA EN EL SUR DE SURAMÉRICA: CRISIS, DIÁlOGO Y NUEVAS PERSPECTIVAS, 2 de março de 2017. Coloquio Iberoamericano. Instituto Max Planck, Heidelberg, 2017.

ALBERDI, Juan Bautista. El crimen de la guerra. [S.1.]: Ed. Librería Histórica, 2004.

ARGENTINA. Constitución Nacional Argentina.

ARGENTINA. Triunvirato. Decreto de Seguridad Individual, de 23 de novembro de 1811. En Estatutos, 1961.

BODIN, Jean. Los seis libros de la Republica. 4 ed. Madrid: Ed. Tercer Milenio Tecnos, 2006.

BROGDANDY, Armin Von. Ius constitutionale commune. In: MAC-GREGOR, Eduardo Ferrer; RAMÍREZ, Fabiola Martínez; MEJÍA, Giovanni A. Figueroa (Coord.). Diccionario de Derecho Procesal Constitucional y Convencional. 2 ed. México: Instituto de investigaciones jurídicas, 2014. p. 774-777.

CALLEWAERT, Johan. Quel avenir pour la marge d'appréciation? In: MAHONEY, Paul; MATSCHER, Franz; PETZOLD, Herbert; WILDHABER, Luzius (Eds.). Protecting Human Rights. Colonia, Berlin, Munich: Carl HeymannsVerlag, 2000. p. 147-166.

CORAO, Carlos Ayala. Del diálogo jurisprudencial al control de convencionalidad. Caracas: Editorial Jurídica Venezolana, 2012. (Colección Estudios jurídicos, n. 98).

DIAZ, José Ramón Cossío. Un mal día para el Sistema Interamericano. El País, Madri, fev. 2017.

FAVOREAU, Louis. El bloque de la constitucionalidad. Revista del Centro de Estudios Constitucionales, n. 5, p. 45-68, ene./mar. 1990.

KANT, Immanuel. Sobre la paz perpetua. Madri: Alianza, 2002.

KELSEN, Hans. Teoría General del Derecho y del Estado. México: UNAM, 1979.

LLORENTE, Francisco Rubio. El bloque de la constitucionalidad. Revista Española de Derecho Constitucional, n. 27, p. 9-37, set./dez. 1989.

MC GREGOR, Eduardo Ferrer. Panorámica del Derecho Procesal Constitucional y Convencional. Madri, Barcelona, Buenos Aires, São Pablo: Instituto de Investigaciones Jurídicas - UNAM, Marcial Pons, 2013.

PIZZOLO, Calogero. Comunidad de intérpretes finales Relación entre tribunales supranacionales, constitucionales y supremos. El Diálogo Judicial. Buenos Aires: Astrea, 2017. 
ROCA, Javier García. El margen de apreciación nacional en la interpretación del Convenio Europeo de Derechos Humanos: Soberanía e integración. Cizur Menor, Navarra: Cuadernos Cívitas, Instituto de Derecho Parlamentario, Thomson Reuters, 2010.

SAGUES, Néstor Pedro. La interpretación de los derechos humanos en las jurisdicciones nacional e internacional. Anticipo de "anales", segunda época, año XLII, n.36, Buenos Aires, p. 14-15, 1998.

SÁNCHEZ, Pablo Antonio Fernández. Naturaleza jurídica de las sentencias del TEDH y del TJCE. In: ROCA, Javier García; SÁNCHEZ, Pablo Antonio Fernández (Coord.). Integración europea a través de derechos fundamentales: de un sistema binario a otro integrado. [S.1.]: Ed. La Jurídica, 2009.

VANOSSI, Jorge Reinaldo A.; DALLA VIA, Alberto Ricardo. Régimen constitucional de los tratados. Buenos Aires: Abeledo Perrot, 2000.

\section{Precedentes judiciais}

ARGENTINA. Corte Suprema de Justicia de la Nacion. Ekmekdjian c. Sofovich. Buenos Aires, 7 de julho de 1992.

. Corte Suprema de Justicia de la Nacion. Fibraca Constructora SCA c/ Comisión Técnica Mixta de Salto Grande. Buenos Aires, 7 de julho de 1993.

Corte Suprema de Justicia de la Nación. Giroldi, Horacio David y otro s/ recurso de casación-causa n. 32/93. Nro. Interno: G000000342. Buenos Aires, 7 de abril de 1995.

Corte Suprema de Justicia de la Nacion. Martín \& Cia. Ltda. SA c. Nación. Buenos Aires, 6 de setembro de 1953.

Corte Suprema de Justicia de la Nacion. Mazzeo, Julio Lilo y otros s/ rec. de casación e inconstitucionalidad-Riveros. Buenos Aires, 13 de julho de 2007.

Corte Suprema de Justicia de la Nacion. Merck Química Argentina c. Governo Nacional. Buenos Aires, 9 de junho de 1948.

Corte Suprema de Justicia de la Nacion. Ministerio de Relaciones Exteriores y Culto. Buenos Aires, 14 de fevereiro de 2017.

Corte Suprema de Justicia de la Nacion. Resolución $n^{o}$ 4015/17. Buenos Aires, 5 de dezembro de 2017.

Corte Suprema de Justicia de la Nacion. Simon, Julio Héctor y otros s/ privación

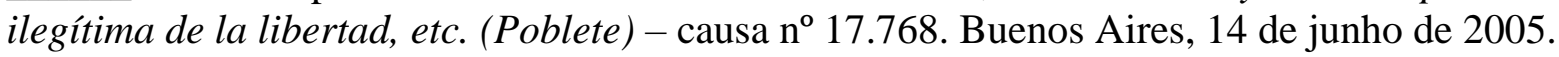


COMISIÓN INTERAMERICANA DE DERECHOS HUMANOS (CIDH). Resolución $n^{\circ}$ 26/88, caso 10109. Argentina, setembro de 1988.

CORTE INTERAMERICANA DE DERECHOS HUMANOS (Corte IDH). Caso Almonacid Arellano y outros vs. Chile. São José, Costa Rica, 26 de setembro de 2006. de 2008 .

Caso Castañeda Gutman vs Mexico, Serie C n 184. São José, Costa Rica, 6 de agosto

Caso Fontevecchia y D'amico vs. Argentina. Supervisión de cumplimiento de sentencia. Resolución de la Corte Interamericana de Derechos Humanos de 18 de outubro de 2017.

Caso Fontevecchia. São José, Costa Rica, 29 de novembro de 2011.

Caso Yatama v. Nicaragua. San José, Costa Rica, 23 de junho de 2005.

Data de Submissão: 01/07/2020

Data de Aceite: 05/08/2020 